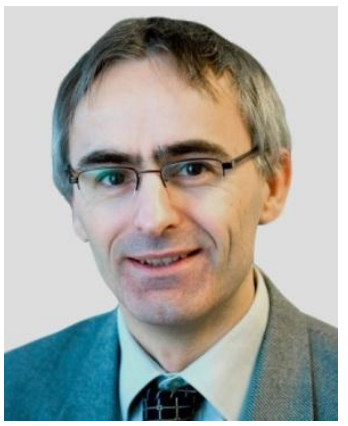

\title{
Power Electronics and Renewable Energy Systems - a perfect match for a sustainable society
}

\author{
Prof. Frede Blaabjerg
}

The energy consumption is steadily increasing very rapid due to more people on the earth, better living conditions as well as we are trying to live in areas where the energy demand is high. The economy growth in the last century has not been possible without low prize of energy which has been achieved by fossil fuels. Looking into the future - the fossil fuel resources have a time limit - which can appear faster than expected - both because of the limited resources but also because the market can suddenly increase the prize. Therefore there is a demand to come up with sustainable energy solutions for energy production like wind turbines, hydro power as well as photovoltaics. At the same time it is evident that by the use of new technology it is possible to make energy saving. In both situations power electronics are making this possible - we are using power electronics to interface renewable sources to maximize the energy yield from wind turbines and photovoltaics as well as smoothly integrate it to the grid. Also in many applications we use power electronics to interface a load with the grid and control the behavior of the electrical equipment according to the demand. In many cases power electronics is able to ensure a large amount of energy saving like in pumps, compressors as well as in ventilation systems. Also the transportation gain a lot of using electricity instead of fossil fuel - clearly made possible due to the power electronics.

Denmark is one of the societies which have been the frontier of implementing the renewable technology and has today covered more than $50 \%$ of the electrical energy consumption by means of renewable and has as ambition to be fully independent on fossil fuels in 2050. Already in $2035100 \%$ of the electricity will be covered by renewables. At the same time the energy consumption has not really increased for 20 years despite the GDP has grown by more than $60 \%$ - much is enabled by energy efficient technologies based on power electronics. So renewables and power electronics are a perfect tool for a sustainable society.

\section{About Prof. Frede Blaabjerg}

Frede Blaabjerg (S'86-M'88-SM'97-F'03) was with ABB-Scandia, Randers, Denmark, from 1987 to 1988. From 1988 to 1992, he was a Ph.D. Student with Aalborg University, Aalborg, Denmark. He became an Assistant Professor in 1992, an Associate Professor in 1996, and a Full Professor of power electronics and drives in 1998. His current research interests include power electronics and its applications such as in wind turbines, PV systems, reliability, harmonics and adjustable speed drives.

He has received 15 IEEE Prize Paper Awards, the IEEE PELS Distinguished Service Award in 2009, the EPEPEMC Council Award in 2010, the IEEE William E. Newell Power Electronics Award 2014 and the Villum Kann Rasmussen Research Award 2014.

He was an Editor-in-Chief of the IEEE TRANSACTIONS ON POWER ELECTRONICS from 2006 to 2012. He has been Distinguished Lecturer for the IEEE Power Electronics Society from 2005 to 2007 and for the IEEE Industry Applications Society from 2010 to 2011 . He is nominated in 2014 by Thomson Reuters to be between the most 250 cited researchers in Engineering in the world. He has more than 1000 publications and more than 37000 citation in Google Scholar. 